\section{Reverse Slot Blot for the Verification of cDNAs Identified through Differential Display}

BioTechniques 34:270-272 (February 2003)

Differential display, first described by Liang and Pardee (4), has become a powerful screening tool for the identification of cell- or stage-specific gene expression. The technique relies on efficient reverse transcription of mRNA and subsequent amplification of this cDNA with as many random primer combinations as possible. RT-PCR products are separated on denaturing sequencing gels, visualized through autoradiography, and bands of interest are eluted from the gel and sequenced. The central focus for improvements to the technique since its inception has been to reduce the high number of false positives and improve the efficiency of reamplification of target genes. During the differential display procedure, there are several sources of false positives. These include cross-contamination of the RNA samples being compared, identically sized fragments co-migrating on the differential display gel, inefficient PCRs, and contamination during the re-amplification process. Numerous methods have been utilized in an attempt to identify false positives. The most common of these is Northern blot analysis (4), which requires large amounts of RNA. Liang et al. (3) and Zimmermann and Schultz (7) resorted to performing duplicate or triplicate RT-PCRs from a single RNA preparation and choosing only reproducible bands for further study. Another approach uses plasmid dot blotting to screen cloned cDNA fragments, using cDNA PCR products as probes (2). Methods to separate co-migrating cDNA fragments include restriction enzyme digestion and partial DNA sequencing (6) and modified singlestranded conformational polymorphism (mSSCP) analysis (5). These methods all have various drawbacks, including lengthy time requirements or the need for large amounts of RNA.
Minimizing the number of procedures that have to be performed for confirmation of results is optimal for any technique aimed at reducing false positives. We have devised a reverse slot blot technique that is performed using re-amplified eluted fragments, thereby eliminating unnecessary subcloning or sequencing reactions.

We have used differential display to identify stage-specific gene expression in the asexual and gametocyte stages of the malaria parasite Plasmodium falciparum, with a view to blocking this transition, which is vital to the transmission of the parasite to its mosquito host.

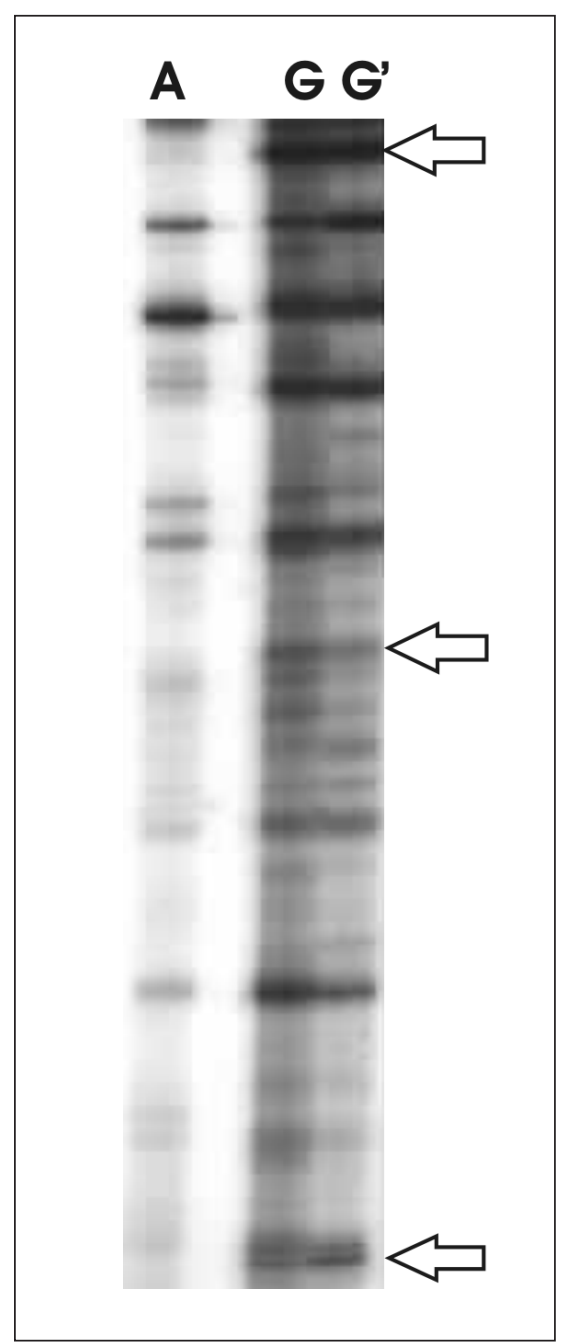

Figure 1. Differential display analysis of $P$. $f a l$ ciparum asexual (A) and gametocyte $\left(G, G^{\prime}\right)$ stage mRNA. Arrows indicate some of the differentially expressed cDNAs. $\mathrm{G}$ and $\mathrm{G}^{\prime}$ represent mRNA preparations from different gametocyte cultures.
Differential display (Figure 1) was performed essentially as described (4). Approximately $200 \mathrm{ng} P$. falciparum strain 3D7 total RNA were reversetranscribed with 2-base anchored primers to select for the $5^{\prime}$ end of the polyA tail, using SuperScript $\mathrm{II}^{\mathrm{TM}}$ RNase $\mathrm{H}^{-}$Reverse Transcriptase (Invitrogen, Carlsbad, CA, USA). The PCR was performed with 11 random 10 - and 13-mers (IDT, Coralville, IA, USA) designed with AT content of $50 \%-70 \%$ to accommodate the high AT content of the $P$. falciparum genome. Each random primer, in combination with each of the 2-base anchored primers, was included in separate reactions to maximize the combinations available for comparison. To isolate gene fragments, the gel was carefully realigned with the autoradiograph, and a sterile scalpel was used to excise the cDNA fragments. A second exposure to X-ray film was then performed to confirm that the correct fragments had been excised. To elute the DNA from the acrylamide gel, the bands were finely sliced and placed in $30 \mu \mathrm{L}$ Milli- ${ }^{\circledR}$ water (Millipore, Bedford, MA, USA). The sample was centrifuged through a pipet filter tip at $10000 \times g$ for $10 \mathrm{~min}$. Ten microliters of this were used for an initial $25-\mu \mathrm{L}$ PCR containing $0.2 \mu \mathrm{M}$ primers, $2.5 \mu \mathrm{L} 10 \times$ Takara PCR Buffer, $0.25 \mu \mathrm{L}$ rTaq DNA polymerase (Takara Bio, Shiga, Japan), and dNTPs at a final concentration of $70 \mu \mathrm{M}$, de-

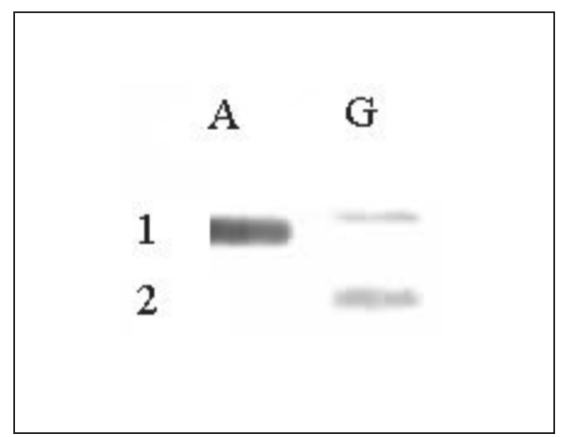

Figure 2. Reverse slot blot to confirm stagespecific expression of differentially displayed P. falciparum gene fragments 1 and 2. RT-PCR was performed with primer combinations designated $55-1 \mathrm{G}$ (55-1 is the arbitrary 13-mer 5' GTCCAATTAGATG-3'; G refers to the 2-base anchored primer polyd $\mathrm{T}_{12} \mathrm{VG}$, where $\mathrm{V}=\mathrm{G}, \mathrm{A}$, and $C$ ). The image shows the up-regulation of fragment 1 in the asexual stages (A) of the parasite and the unique expression of fragment 2 in gametocytes $(\mathrm{G})$. 
noted PCR1. One microliter of PCR1 was used as a template for a second PCR, which was set up in triplicate, pooled, precipitated with ethanol, and resuspended in a final volume of $20 \mu \mathrm{L}$ Milli-Q water. Two microliters were assessed on a standard 1\% agarose gel. Using this technique, we attained a reamplification rate of greater than or equal to $90 \%$.

To verify that the re-amplified products were indeed expressed in a stagespecific manner, we developed a modified reverse slot blot technique (Figure 2). In brief, $2-5 \mu \mathrm{L}$ re-amplified DNA, representing 70-90 $\mathrm{ng}$, were added to $195 \mu \mathrm{L}$ denaturing solution $(0.4 \mathrm{M}$ $\mathrm{NaOH}, 25 \mathrm{mM}$ EDTA) and denatured at $95^{\circ} \mathrm{C}$ for $2 \mathrm{~min}$. This was then transferred onto nylon membranes (Amersham Biosciences, Little Chalfont, UK) and UV cross-linked for $4 \mathrm{~min}$ at 302 nm. $\alpha-32$ P RT-PCR products from new asexual and gametocyte preparations were prepared as described above.
Identical concentrations of asexual stage and gametocyte RNA were used for the RT-PCRs, which were performed with the original primer combinations from the differential display gel. Blots were placed in $5-\mathrm{mL}$ test tubes and probed with $800 \mu \mathrm{L}$ hybridization buffer $(5 \times$ SSPE, $5 \times$ Denhardt's solution, $0.5 \%$ SDS) containing up to $25 \mu \mathrm{L} \alpha-32 \mathrm{P}$ RT-PCR products. Asexual and gametocyte probe concentrations were normalized by comparing the incorporation of $\alpha[32 \mathrm{P}] \mathrm{dATP}$, assessed by $10 \%$ TCA precipitation and liquid scintillation counting (1). To confirm differentially expressed fragments that originated from different primer combinations, all $\alpha-32 \mathrm{P}$ RTPCR products were combined to probe a single blot. The blot was washed in $0.2 \times \mathrm{SSC} / 0.1 \% \mathrm{SDS}$ for $10 \mathrm{~min}$ with vigorous rotation at room temperature, followed by a similar wash at $65^{\circ} \mathrm{C}$. Stringency was varied if necessary, according to standard protocols (1). The blot was exposed to X-ray film for 30 min in a cassette containing enhancing screens. Exposure times were varied according to signal intensity.

This novel, sensitive, and rapid method ascertains both the reproducibility of the differential display technique and the authenticity of differential display results. Since the probe is an RT-PCR product and re-amplified cDNA fragments are immobilized on the membrane, only small quantities of RNA are required (50-500 ng). The technique is highly sensitive, and eluted fragments can be verified as being true positives within two days of reamplification.

\section{REFERENCES}

1.Ausubel, M.F., R. Brent, R.E. Kingston, D.D. Moore, J.G. Seidman, J.A. Smith, and K. Struhl. 2000. Current Protocols in Molecular Biology. John Wiley \& Sons, New York.

2.Callard, D., B. Lescure, and L. Mazzolini. 1994. A method for the elimination of false positives generated by the mRNA differential display technique. BioTechniques 16:10961102.

3.Liang, P., L. Averboukh, and A.B. Pardee. 1993. Distribution and cloning of eukaryotic mRNAs by means of differential display: refinements and optimisation. Nucleic Acids Res. 21:3269-3275.

4.Liang, P. and A.B. Pardee. 1992. Differential display of eukaryotic messenger RNA by means of the polymerase chain reaction. Science 257:967-970.

5.Miele, G., L. Macrae, D. McBride, J. Manson, and M. Clinton. 1998. Elimination of false positives generated through PCR re-amplification of differential display cDNA. BioTechniques 25:138-144.

6.Zhao, S., S.L. Ooi, F-C. Yang, and A. B. Pardee. 1996. Three methods for identification of true positive cloned cDNA fragments in differential display. BioTechniques 20:400404.

7.Zimmerman, J.W. and R.M. Schultz. 1994 Analysis of gene expression in the preimplantation mouse embryo: use of mRNA differential display. Proc. Natl. Acad. Sci. USA 91:5456-5460.

Funding for this research has been $o b-$ tained from, University of the Witwatersrand, National Health Laboratory Services, National Research Foundation, and Medical Research Council of South Africa. Original stocks of $\mathrm{P}$. falciparum strain $3 D 7$ were a gift from the Department of Pharmacy and Pharmacology of the University of the Witwatersrand. Address correspondence to $\mathrm{Mr}$. Daniel R. Meyersfeld, Department of Molecular Medicine and Haematology, University of the Witwatersrand, 7 York Road, Parktown, 2193 Johannesburg, South Africa. e-mail: danny.meyersfeld@ananzi.co.za

Received 6 September 2002; accepted 28 October 2002.

\section{Daniel R. Meyersfeld ${ }^{1}$ and \\ Thérèsa L. Coetzer ${ }^{1,2}$ \\ ${ }^{1}$ University of the \\ Witwatersrand \\ ${ }^{2}$ National Health Laboratory \\ Services \\ Johannesburg, South Africa}

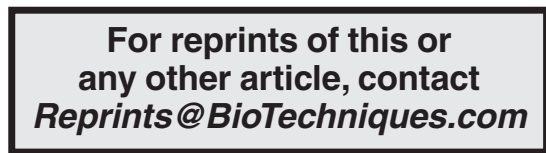

Vol. 34, No. 2 (2003) 